\title{
THE VALIDITY OF TEXTBOOK BASED ON READING, QUESTIONING AND ANSWERING (RQA) FOR LEADING STUDENTS IN ASSESSMENT COURSE AT CHEMISTRY DEPARTMENT UNESA
}

\author{
Harun Nasrudin ${ }^{* 1}$, Utiya Azizah², Muchlis ${ }^{3}$ \\ 1,2,3 Jurusan Kimia, FMIPA, Universitas Negeri Surabaya \\ *Corresponding author: harunnasrudin@unesa.ac.id
}

\begin{abstract}
This study aims to determine the validity of textbook based Reading, Questioning and Answering (RQA) in process assessment and learning outcomes course at chemistry department Unesa. The research method uses research and development $(R \& D)$. The results showed that the textbook based RQA was feasible in term of construct validity with very valid category, content validity with very valid category, language and readability with valid category, and in accordance with the RQA strategy with a valid category. From this research, it can be concluded that the texbook suitable for use in process assessment and learning outcomes course.
\end{abstract}

Keywords: validity, textbook based RQA, assessment course

\section{PENDAHULUAN}

Untuk meningkatkan mutu pendidikan di Perguruan Tinggi salah satunya adalah dengan memanfaatkan sumber belajar. Pernyatan tersebut sejalan dengan suatu pendapat bahwa salah satu faktor yang menyebabkan rendahnya kualitas perkuliahan antara lain belum dimanfaatkannya sumber belajar secara maksimal [1]. Hal tersebut lebih dipersulit lagi oleh suatu kondisi dimana dosen mendominasi kegiatan perkuliahan, yang seharusnya dapat dilakukan dengan mendayagunakan sumber belajar yang bervariasi. Berdasarkan hal tersebut, untuk memperoleh hasil belajar yang optimal, mahasiswa dituntut tidak hanya mengandalkan dari apa yang terjadi di dalam kelas, tetapi harus mampu dan mau menelusuri aneka ragam sumber belajar yang diperlukan.

Buku ajar merupakan salah satu sumber belajar. Buku ajar yang dikembangkan dosen pengampu mata kuliah, sangat diperlukan dalam setiap proses perkuliahan untuk memudahkan mahasiswa memperoleh bahan bacaan yang sesuai dengan materi perkuliahan. Buku ajar merupakan salah satu bahan ajar yang bersumber dari beberapa literatur yang relevan terhadap kompetensi dasar dan materi pokok serta memudahkan mahasiswa dalam proses perkuliahan [2].

Mata kuliah 'Asesmen Proses dan Hasil Belajar (APHB)' di jurusan kimia diselenggarakan untuk seluruh mahasiswa program studi pendidikan kimia sebagai calon guru termasuk di kelas unggulan. Mata kuliah APHB membahas tentang konsep dasar penilaian, perancangan, dan penerapannya. Materi-materi dalam mata kuliah APHB memiliki karakteristik bersifat teoritis atau berupa teks-teks bacaan. Berdasarkan karakteristik materi dalam mata kuliah APHB tersebut, diperlukan kemampuan membaca teks dengan baik dan terorganisir agar istilahistilah dan konsep-konsep yang terdapat pada materi tersebut dapat dipahami dengan baik dan kualitas perkuliahan dapat meningkat. Mahasiswa kelas unggulan diharapkan memiliki kemampuan berkomunikasi dalam bahasa Inggris. Oleh karena itu, pengembangan buku ajar pada mata kuliah APHB di program studi pendidikan kimia kelas unggulan yang berbahasa Inggris sangat diperlukan.

Kualitas perkuliahan merupakan salah satu unsur dari paradigma baru pengelolaan pendidikan di perguruan tinggi. Oleh karena itu dosen memiliki tanggung jawab yang besar dalam membentuk pengalaman belajar mahasiswa. Salah satu bentuk tanggung jawab itu adalah dengan menggunakan strategi pembelajaran yang inovatif yang diharapkan dapat meningkatkan hasil belajar kognitif mahasiswa. 
Salah satu strategi pembelajaran konstruktivis yang dapat digunakan yang sesuai dengan fakta terkait karakteristik materi dalam matakuliah APHB dan dituangkan dalam Buku Ajar tersebut adalah pembelajaran Reading, Questioning, and Answering (RQA) [3]. Strategi RQA diawali dengan tahap reading yaitu mahasiswa diberi tugas untuk membaca dan memahami bacaan materi, mengidentifikasi ide-ide penting dan menemukan kata kunci sehingga mampu menemukan konsep-konsep esensial dalam materi tersebut, selanjutnya pada tahap questioning mahasiswa membuat daftar pertanyaan terkait konsep-konsep penting yang ditemukan ketika mencermati materi, dan pembelajaran diakhiri pada tahap answering yaitu mahasiswa memprediksi jawaban dari pertanyaan yang telah dibuat.

Buku ajar yang dikembangkan dikatakan berkualitas jika memenuhi kriteria, yaitu validitas, kepraktisan, dan efektivitas [4]. Buku ajar dikatakan valid apabila ada keterkaitan yang konsisten dari setiap komponen buku ajar yang dikembangkan dengan karakteristik strategi pembelajaran yang diterapkan.

\section{METODE}

Jenis penelitian ini adalah penelitian pengembangan menggunakan kerangka berpikir Research and Development (R \& D) [5]. Produk yang dihasilkan pada penelitian ini adalah buku ajar untuk mata kuliah APHB berbasis pembelajaran reading, questioning, and answering (RQA).

Tahapan penelitian ini meliputi studi pendahuluan dan pengembangan buku ajar. Pada studi pendahuluan, dilakukan analisis konsep dan teori yang berkaitan dengan buku ajar yang dikembangkan dan identifikasi karakteristik mahasiswa. Pada tahap pengembangan disusun draf awal buku ajar. Pemilihan format, media, referensi, dan perancangan awal buku ajar merupakan kegiatan utama tahap ini.

Buku ajar yang berhasil dikembangkan selanjutnya divalidasi secara teoritis (konstruk dan isi) oleh ahli / pakar dalam bidang pendidikan kimia. Untuk keperluan penilaian ahli disiapkan instrumen validasi untuk menilai dan memberi masukan terhadap buku ajar yang dikembangkan.

Analisis data hasil validasi dilakukan terhadap masing-masing kriteria dan aspek pada lembar validasi meliputi kriteria konstruk, kriteria isi, bahasa dan keterbacaan, serta kesesuaiannya dengan RQA.

\section{HASILDAN PEMBAHASAN}

Hasil analisis konsep-konsep utama yang berkaitan dengan buku ajar yang dikembangkan disajikan dalamTabel 1 .

Tabel 1 Konsep-konsep utama pada materi-materi dalam buku ajar Asesmen

\begin{tabular}{ll}
\hline \multicolumn{1}{c}{ Materi } & \multicolumn{1}{c}{ Konsep-konsepUtama } \\
\hline Role of Assessment in & Assessment, basic of competencies, Core Competencies, Minimum \\
Learning & Mastery Criteria, indicators, remedial program, enrichment \\
& program, measurement, evaluation, assessment of learning, \\
& assessment for learning, assessment as learning, self-assessment, \\
& peer-assessment, valid, objective, equitable, criteria-referenced \\
& assessment, Graduates Competency Standards.
\end{tabular}

Bloom's taxonomy and the Development of Indicators of Competencies Achievement

Authentic Assessment of Knowledge, Skills, and Attitude
Bloom's taxonomy, cognitive domain, knowledge dimension, factual knowledge, concept, procedural knowledge, metacognitive, cognitive process dimension, remember, understand, apply, analyze, evaluate, create, competence achievement indicators, high order thinking skill (HOTS), learning objective, question indicator, audience, behavior, conditions, degree.

Knowledge assessment, basic competencies, lesson plan, syllabus, written test, oral test, assignment, true-false, multiple choice, match up, stuffing test, essay, quizzes, task, objective test, selection, placement, diagnostic, formative, summative, writing rules, qualitative analysis, skill assessment, performance 


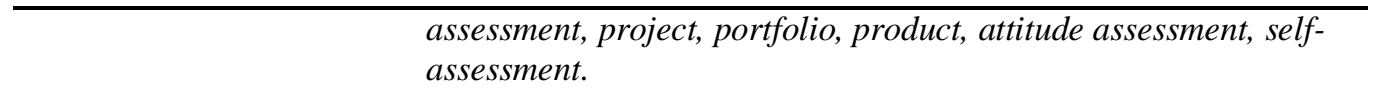

Planning of Test and Non-Test
Selection test, multiple choice item, stem, options, true-false items, matching items, premise, responses, supply items, short answer, completion items, scoring, decision making, analytical scoring, holistic scoring, assessment rubric.
Dengan menggunakan konsep-konsep hasil analisis, disusun draf awal (prototipe) buku ajar APHB berbasis pembelajaran RQA, dan dilanjutkan dengan kegiatan validasi buku ajar.

Secara umum, data persentase ketercapaian validitas buku ajar yang dikembangkan menurut penilaian validator dan mahasiswa disajikan pada Gambar 1.

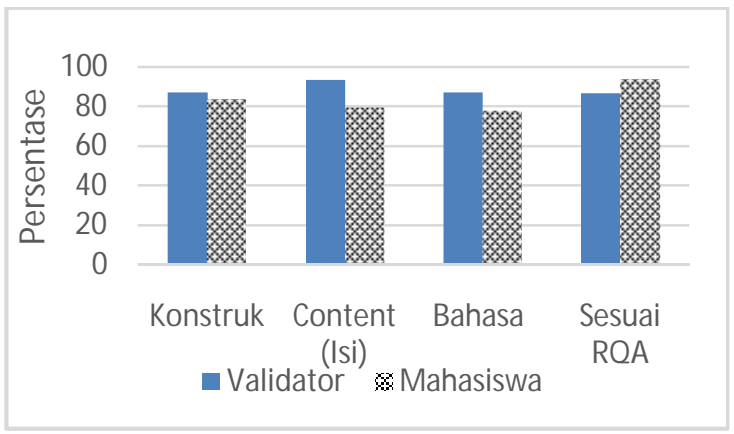

Gambar 1. ValiditasBuku ajar APHB

Berdasarakan Gambar 1, terlihat bahwa persentase hasil penilaian validator dan mahasiswahampir mirip untuk semua kriteria. Hal ini berarti penilaian dari validator maupun mahasiswa, diperoleh pernyataan yang sama bahwa buku ajar yang dikembangkan telah memenuhi kriteria $R Q A$, karena berdasarkan aspek-aspek yang dinilai oleh validator danmahasiswa, terlihat bahwa persentase ketercapaian validitas memiliki rentang80\% sampai $100 \%$ dengan kriteria valid dan sangat valid serta baik dan sangat baik [6]. Dengan demikian dapat dinyatakan bahwa buku ajar asesmen berbasis $R Q A$ yang dikembangkan telah valid dan dapat digunakan dalam proses perkuliahan.

Penilaian validator terhadap kriteria konstruk buku ajar APHB berbasis pembelajaran RQA untuk materi yaitu Role of Assessment in Learning, Bloom's Taxonomy and the Development of Indicators of Competencies Achievement, Authentic Assessment of Knowledge, Skills, and Attitude serta Planning of Test and Non-Test adalah sangat valid dengan rentang persentase validitas antara $80 \%$ - 100\%. Hal ini berarti, buku ajar tersebut telah lengkap dan baik meliputi cover mempresentasikan isi buku ajar, introduction berisi deskripsi singkat isi $\mathrm{Bab}$ dan tujuan pembelajaran, tujuan pembelajaran telah dituliskan secara operasional, material berisi materi dalam buku ajar yang relevan dengan tujuan pembelajaran dan telah merangkai konsep-konsep penting, tabel/ilustrasi/gambar memperjelas materi, individual assignment berisi kegiatan mahasiswa dalam memahami isi bacaan (membaca), membuat pertanyaan, dan menjawab pertanyaan yang dibuat, dan terdapat daftar pustaka.

Validitas content (isi) atau materi dalam buku ajar yang dikembangkan telah sesuai dengan kurikulum yang berlaku, dan benar ditinjau dari segi keilmuan [7]. Buku ajar tersebut juga memperhatikan kemutakhiran konten, dan disusun secara sistematis sehingga sesuai dengan struktur keilmuan. Kemutakhiran konten diperkuat oleh suatu pendapat yang menjelaskan bahwa materi buku ajar sangat baik jika menggunakan referensi-referensi mutakhir yang memiliki relevansi dari berbagai sumber misalnya buku, internet, majalah, jurnal hasil penelitian [8].

Validitas pada penyajian content (isi) atau materi dalam buku ajar juga ditunjukkan dengan aspek menarik dan menyenangkan sehingga dapat membangkitkan motivasi mahasiswa untuk belajar, sesuai dengan kemampuan dan taraf berfikir mahasiswa, dan mendorong mahasiswa untuk terlibat secara aktif dalam kegiatan perkuliahan. Keterlibatan aktif mahasiswa dalam perkuliahan sesuai dengan hasil penelitian pengembangan perangkat pembalajaran termasuk buku ajar yang menemukan bahwa kegiatan-kegiatan dalam buku ajar dapat membantu mahasiswa dalam membangun pengetahuannya sendiri [9].

Validitas bahasa dan keterbacaan dalam buku ajar ditunjukkan dengan bahasa yang digunakan telah sesuai dengan usia mahasiswa. Selain itu istilah yang digunakan 
tepat, mudah dipahami, dan menggunakan simbol secara ajeg. Fakta tersebut diperkuat oleh suatu pendapat bahwa penggunaan buku ajar dalam perkuliahan mampu menarik perhatian mahasiswa apabila buku ajar dilengkapi dengan gambar yang berwarna dan menggunakan kalimat yang mudah dipahami mahasiswa [2].

Buku ajar yang dikembangkan menunjang keterlaksanaan proses perkuliahan yang lebih diwarnai oleh student centered daripada teacher centered karena mahasiswa secara mandiri belajar memahami konsep. Dalam buku ajar, tampak pada individual assignments yang membimbing dan mengarahkan mahasiswa dalam menemukan konsep melalui membuat ringkasan materi, membuat pertanyaan-pertanyaan secara tertulis, dan memprediksi jawabnya sendiri.

Revisi dilakukan sesuai dengan tanggapan dan saran yang diberikan oleh setiap ahli baik yang diberikan secara langsung maupun yang tertulis pada kolom saran. Saran dari tim ahli dan revisi yang dilakukan oleh peneliti seperti yang terdapat padaTabel 2 .

Tabel 2

\begin{tabular}{|c|c|}
\hline Saran & Revisi Peneliti \\
\hline $\begin{array}{l}\text { Menambahkan } \\
\text { keterangan dan sumber } \\
\text { pustaka pada beberapa } \\
\text { gambar }\end{array}$ & $\begin{array}{l}\text { Keterangan dan } \\
\text { sumber pustaka pada } \\
\text { beberapa gambar } \\
\text { ditambahkan }\end{array}$ \\
\hline $\begin{array}{l}\text { Menambahkan } \\
\text { penjelasan tentang } \\
\text { level kognitif terkait } \\
\text { pertanyaan yang harus } \\
\text { muncul dari } \\
\text { mahasiswa } \\
\end{array}$ & $\begin{array}{l}\text { Penjelasan tentang } \\
\text { level kognitif terkait } \\
\text { pertanyaan yang harus } \\
\text { muncul dari } \\
\text { mahasiswa } \\
\text { ditambahkan } \\
\end{array}$ \\
\hline
\end{tabular}

Saran yang diberikan menekankan pada aspek penyajian masalah dan keterbacaan agar mahasiswa lebih mudah dalam memahami dan memotivasi mahasiswa dalam belajar

\section{SIMPULAN DAN SARAN}

Berdasarkan penelitian yang dilakukan dapat disimpulkan bahwa buku ajar yang dikembangkan melalui $\mathrm{R} \& \mathrm{D}$ pada mata kuliah'Asesmen Proses dan Hasil Belajar (APHB)' telah memenuhi kriteria valid berdasarkan kriteria konstruk, isi, bahasa dan keterbacaan, serta kesesuaian dengan pembelajaran RQA.

\section{DAFTAR PUSTAKA}

[1] Mulyasa, E. (2007). Menjadi Guru Profesional menciptakan Pembelajaran Kreatif dan Menyenangkan. Bandung: Rosdakarya

[2] Prastowo, A. (2011). Paduan Kreatif Membuat Bahan Ajar Inovatif. Yogyakarta: Diva Press

[3] Corebima, A. D. (2009). Pengalaman Berupaya Menjadi Guru Profesional. Pidato Pengukuhan Guru Besar pada FMIPA UM. Disampaikan pada Sidang Terbuka Senat UM, Malang, 30 Juli.

[4] McKenney, S., Nieveen, N. \& van den Akker, J. (2002). Computer Support for Curriculum Developers: CASCADE. ETR\&D. 50(4): 25-35

[5] Borg, W.R. \& Gall, M.D. (2003). Educational Research. New York: Longman.

[6] Riduwan. (2012). Skala pengukuran variabel-variabel penelitian. Bandung: Alfabeta.

[7] Nur, Mohamad. (2002). Model Buku Pelajaran Mata Pelajaran Fisika SMU. Surabaya: Program Pasca SarjanaUnesa.

[8] Depdiknas. (2008). Panduan Pengembangan Bahan Ajar. Jakarta: Depdiknas.

[9] Azizah, Utiya \& Nasrudin, Harun (2013). Pemberdayaan Kecakapan Berpikir Siswa SMA Bertaraf Internasional Melalui Pengembangan Perangkat Pembelajaran Materi Redox Reaction Berorientasi "Group Investigation Cooperative."Jurnal Pendidikan dan Pembelajaran (JPP). Terakreditasi ISSN 2302-996X. Vol 20. No 2. pp. 141-151. 